\title{
Research on the Platform Construction of Road Freight Market in China
}

\author{
Xingang Weng, Jitang Geng \\ Beijing Wuzi University, Beijing, China \\ Email: noune20@163.com
}

Received 15 May 2015; accepted 9 June 2015; published 12 June 2015

Copyright (C) 2015 by authors and Scientific Research Publishing Inc. This work is licensed under the Creative Commons Attribution International License (CC BY). http://creativecommons.org/licenses/by/4.0/

\section{(c) (i) Open Access}

\begin{abstract}
Against the backdrop of the boom in logistics industry, road freight is undertaking an increasingly important responsibility as the leading mode of cargo transportation. However, the road freight resources in our country cannot adequately meet the needs at present, due to the poor status quo of large overall scale and small individual size, the dispersion and disunity of freight, and low effective utilization. It has become a hot topic about how to better promote the wholesome and efficient advance of our domestic road freight market, for which our government, scholars or enterprises have made tremendous studies and attempts. Nevertheless, with regard to the deficiencies in the related studies, how to better use the platform in the service of its resource integration turns out to be the key of the problem. This paper by taking account the disperse condition of the road freight market resources, emphasizes the analysis of the operation mode and means of integration of the road freight platform by citing living examples as arguments for exploration and improvement, to make an systematic research; the road freight resources being the objects, platform the means, and integration the target. On account of the platform to conduct the integration, it is expected to achieve better market condition and higher efficiency, thus laying a theoretical foundation for its practical operations.
\end{abstract}

\section{Keywords}

Road Freight, Platform, Resource Integration

\section{Analysis on the Development and Present Situation of Road Freight Market in China}

\subsection{Current Development Situation of the Road Freight Market in China}

The main distribution situation of the road freight market at present in our country has a long history. In the be- 
ginning, supplies were controlled by the state; the goods were transported by the state or collective freight enterprises; and individual road freight was impossible as a result. At that time, road freight transport capacity and traffic volume were radically unbalanced. Vehicles and goods could not be matched to each other. Private road freight enterprises in our country began to flourish under the influence of reform and opening-up policy, which has basically satisfied the needs of the road freight at home.

Part of the road freight practitioners started to transform from general road freight services to professional logistics service after $21^{\text {st }}$ century; then a variety of transportation and warehousing companies transformed to logistics enterprises. Although some companies started to integrate resources on a large scale in the form of shipping alliance or merger, the overall number is too small, unable to form a certain scale (shown in Figure 1). Most of the small logistics enterprises commonly use the original traditional way to freight, vehicle ownership on average less than 3 units. They have a high empty rate; technology and equipment have no substantial ascension and freight transport mode doesn't happen substantive change [1].

As the main form of road freight transport in our country, the road cargo transport market has not yet been fundamental changed: the transportation market structure does not adapt to market development, and freight enterprise market structure is dominated by small miniature. Existing regional or national large-scale backbone freight enterprise scale is small, and can't lead the development trend of road transport market. The industry is difficult to maximize production efficiency or form effective competition. So market structure also needs to be further optimized and improved.

From Table 1, we can see that we have many companies of road freight. However, the individual businesses are 5.188 million and the proportion reaches to $88.5 \%$ of the road freight companies. Besides in the road freight enterprises of the country, $91.3 \%$ of the freight companies have less than 10 vehicles, and the market concentration and road freight resources utilization rate are low.

\subsection{Comparative Analysis of the Road Freight Industry Development Situation in China and Foreign Country}

Compared with the foreign country, there are a lot of road freight markets both in external environment, internal management and technology in China need to be developed and improved. The disordered market main body and low resource utilization need to be improved. And there is a big difference on the road freight concentration between our country and countries of Europe and America. And the road freight market concentration refers to the total market share of the largest N-road freight enterprises in the market, also known as the market concentration rate, and it is generally denoted by CRN ( $\mathrm{N}$ presented the number of the enterprises). The road freight market concentration occupies an important position in the whole road freight organization theory, and it is also one of the standards to measure the degree of road freight intensive development.

We can see that from the Table 2, the American company has a great scale of road freight, and it has a great relationship with the series of policy change of highway transportation and the change of industrial structure from $20^{\text {th }}$ century. The road freight market was also developed from the original scattered capacity step by step integration. In addition, to promote the road freight transportation technology and efficiency is also worthy of our learning place.

\section{Construction of Road Freight Transportation Platform Model}

We endeavor to build development patterns of the platform that can integrate the road transport market resources

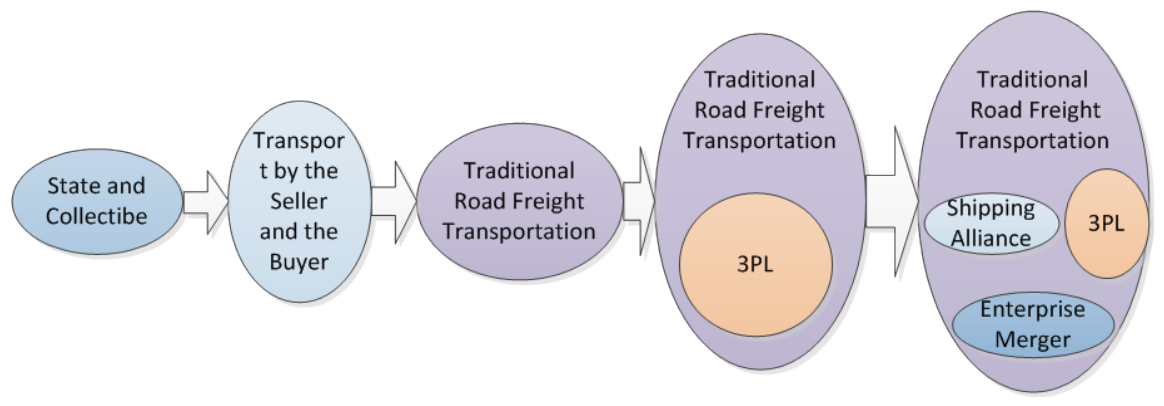

Figure 1. The transition of the road freight main structure in China. 
Table 1. The country road freight transport business operators in 2010.

\begin{tabular}{ccccc}
\hline Type & Total & Enterprise & Personal & Proportion of personal in all (\%) \\
\hline General cargo transport (number of companies by thousand) & 59 & 674 & 5185 & 88.5 \\
Special cargo transport (number of companies by thousand) & 42 & 23 & 19 & 45.1 \\
Container transportation (numbers of companies) & 9896 & 8993 & 903 & 9.1 \\
Large objects transportation (numbers of companies) & 4913 & 2455 & 2458 & 50 \\
Dangerous cargo transport (numbers of companies) & 9271 & 9230 & 41 & 0.4 \\
Total (number of companies by thousand) & 5883 & 695 & 5188 & 88.5 \\
\hline
\end{tabular}

Data source: Report to the development of China's road transport 2010 [2].

Table 2. Our country road freight market concentration compared with Europe and America.

\begin{tabular}{|c|c|}
\hline Countries/regions & Concentration analysis \\
\hline China & $\begin{array}{l}\text { Decentralized road freight market main body, the top five road freight companies have less than } \\
\qquad 2 \% \text { of the market share. }\end{array}$ \\
\hline Europe & The market is relatively mature, 5 big LCL company occupy market share of about $28 \%$. \\
\hline America & Market concentration is high, the top five big freight companies account for $60 \%$ of the market. \\
\hline
\end{tabular}

Data source: 2013 China Freight Logistics Industry Report [3].

effectively from the aspects of main body, needs, network and service. For this purpose, we strive to build the road freight transportation mode to realize resource conformity from the view of online and offline linkage, positive cross-network effects of the multilateral market and ecosystem construction of road freight platform.

\subsection{Coordinated Linked between Online and Offline}

Road freight platform internal resources form an organic system. Despite the fact that it operates through online and offline integration, but it runs service rather than usual tangible goods.

This platform runs dynamically, instead of virtual integration as general platforms which is not adequate. To elevate the market transaction efficiency, entitative platform needs to be constructed. These platforms are structured in capacity, strategies, and knowledge. Thus, these are social division of labor and coordination, advancing of the platform system with the times and value creation recognized by customers and others that determine the gradual development of the plat form.

Platforms are characterized with a myriad of modes and methods to operate. Their function is divided into two categories on the whole, namely online and offline integration. The existing freight information sharing platform is online integration in general. Nevertheless, if you want to achieve a good running state, online and offline unified operation mechanism is required for a higher level of integration, as shown in Figure 2.

\subsection{Positive Cross Network Effects of Road Freight Platform Multilateral Market}

There are more than two groups to participate in the road freight platform, including not only the buyers and sellers of goods but also the freight companies. An open network will take form between them. As platform links the volatile market, all the participants take part in the platform and there is demand for road freight platform at the same time, platform can generate value and the changeable market of road freight can be run (shown in Figure 3). Inroad freight transport platform, when there is a sudden increase or decrease in the supply of the ships, road freight enterprises and demand for goods changes accordingly, the same changes happen in turn, which is how the multilateral market network externality plays its role [4].

During the operation of road freight platform, multilateral market structure plays a decisive role. In balancing the size of all parties of the road freight platform, each side of the freight suppliers and demanders and the shippers and their interaction are also determinate. As a result, the multilateral market can maintain the balance of the road freight platform. 


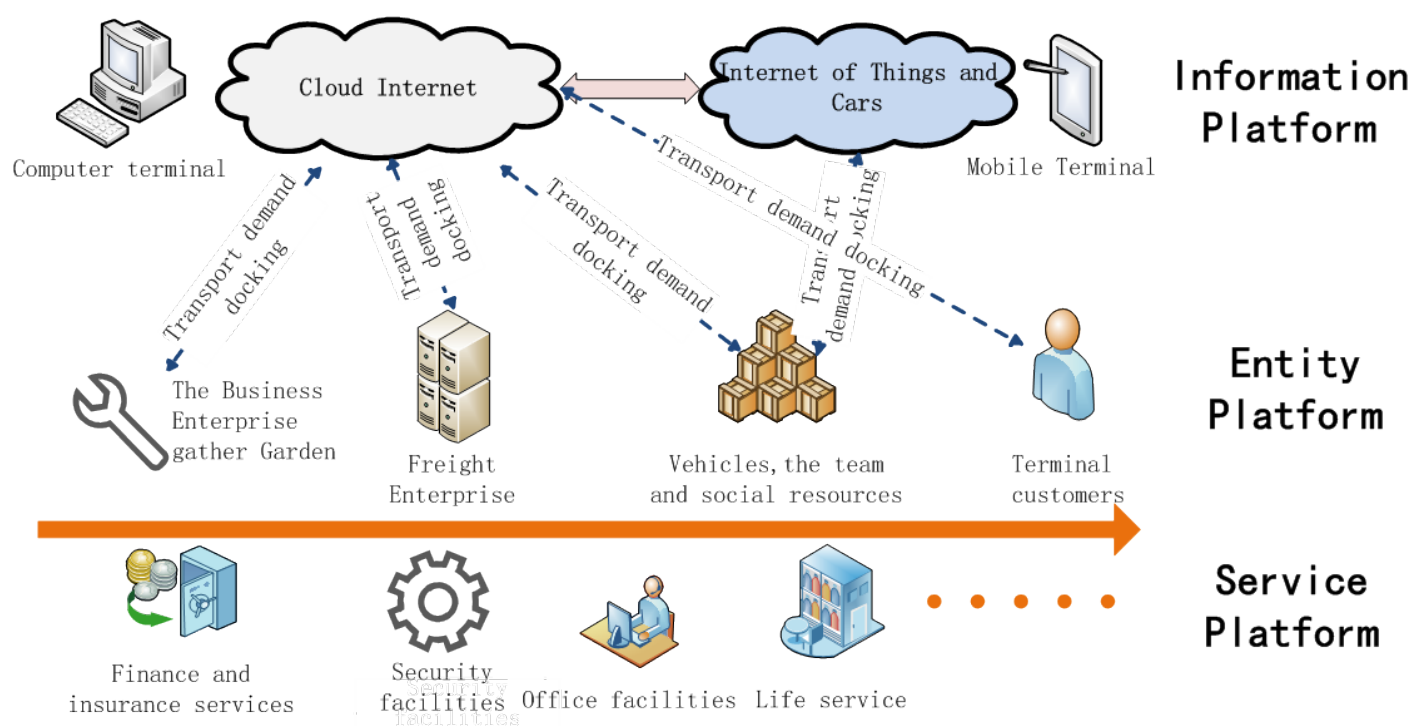

Figure 2. Structure of road freight platform.

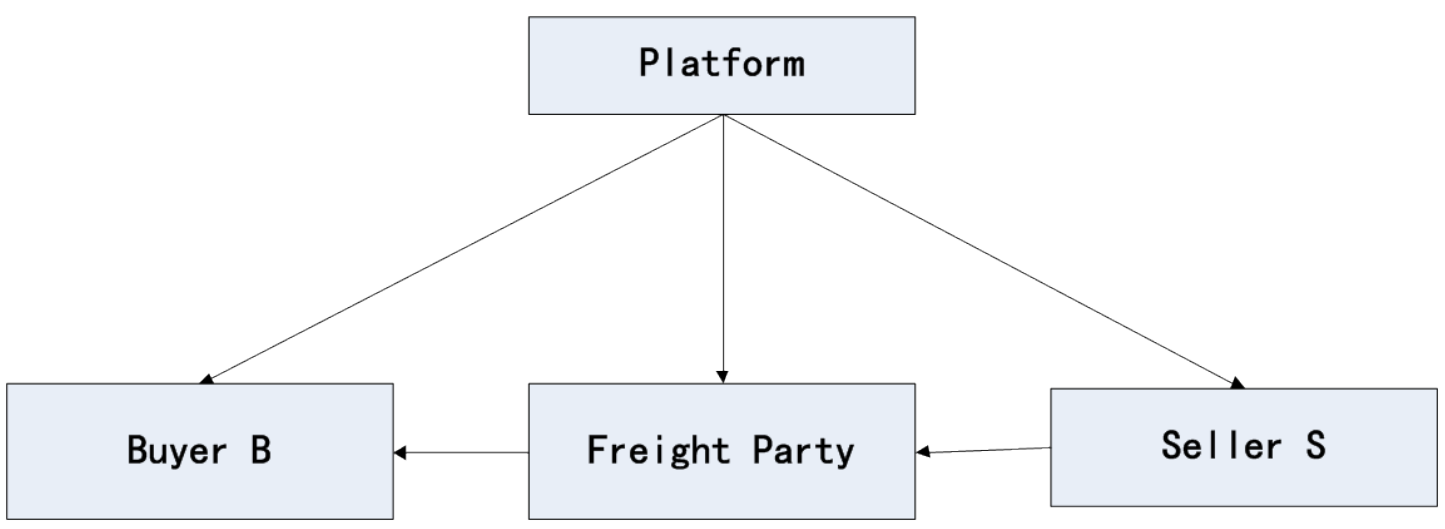

Figure 3. Changeful market structure of freight foundation platform.

The construction of the changing market of the road freight platform should be accorded to the network externality and the positive cross-network effect among the internal multilateral markets to explore their internal connection inside and attract customers from different markets by marketing. As shown in Figure 4, as long as the number of users in one side are brought in, the unique positive cross-internet effect of the road freight platform will spur customers on the other sides to enter in, thus forming a virtuous circle. Still, if it is not handled properly in the construction, it will cause the loss of some customers, the same structural properties will lead to more loss of them, thereby affecting the operation of the entire road freight platform.

\subsection{Ecosystem Construction of Road Freight Platform}

The road freight platform can not depart from the platform system during the operation, the entire system will constitute the equal ecosystem, when we build the platform we should take into account the construction of entire platform ecosystem, the internal of ecosystem should adopt "the government, enterprises, banks, society" form four groups of social interaction", we can follow the closeness of the relationship in the mutual relationship between the body, the road freight platform ecosystem is constructed from three levels: core, expansion and peripheral (shown in Figure 5) [5].

The classification of three levels will help us to distinguish the primary and secondary factors from business ecosystem, and thus promote to category management, prioritizing and weighting, which promoting the healthy development of the platform ecosystem. What is worth noting that not every ecosystem plays a role in the 


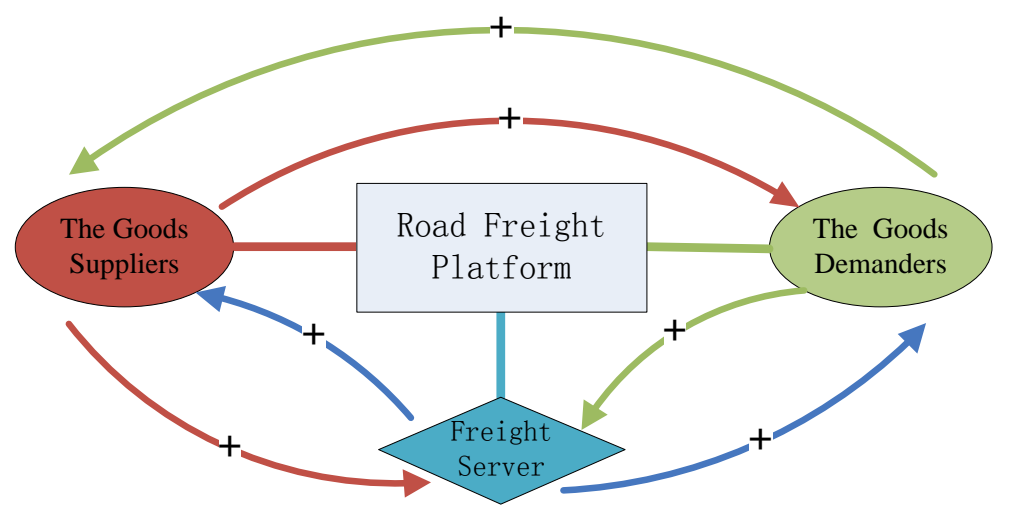

Figure 4. Positive cross network effects of road freight platform multilateral market.

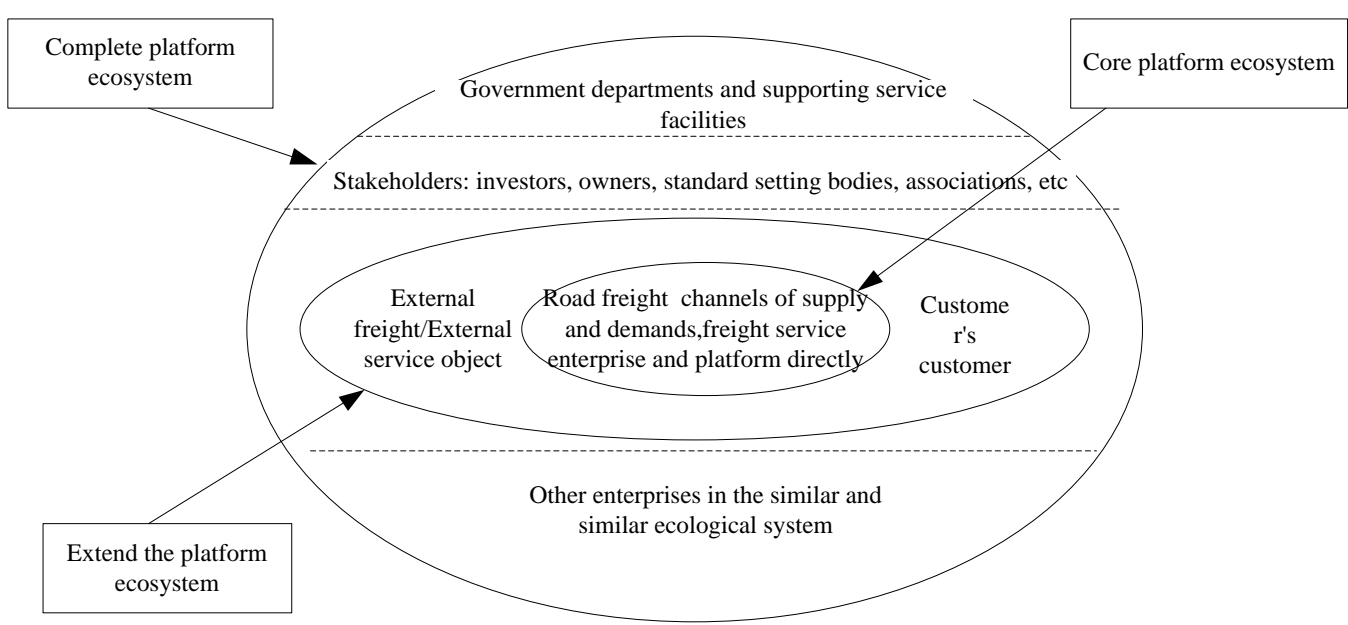

Figure 5. Structure model of the road freight platform ecosystem.

foundation of various platforms. However, the contrary is that only forming of ecosystem can the operation of platform be achieved. It is because the platform itself is only semi-finished products and the products and services are very limited itself, which does not complete, in order to operate effectively together it needs the form of platform ecosystem.

\section{Road Freight Platform Instance Analysis}

We will analysis three well-known road freight platform companies: Transfar Road-port, ANE and Kaxing Tianxia. We can see that they are the same in the whole operation model structure and core, but there is a little difference in the ideas and means of integration.

\subsection{Analysis on the Difference of Road Freight Platforms Running Mode}

We can see the difference of road freight platforms running mode above (shown in Table 3), and analysis the difference from the subject integration mode and the operational thinking.

\subsubsection{Freight Subject Integration Mode Analysis}

Transfar Road-port: It is equivalent to a market to give the platform let every road freight subject freedom to participate in. And it provide site, informations and channels for the customer, but the general management is run by the themselves.

Kaxing Tianxia: It does not build the network hub, but is formed from main body to join. It is just a platform 
Table 3. Operational differences between Transfar Road-port, Kaxing and ANE.

\begin{tabular}{cccc}
\hline Platform for enterprise & Transfar Road-port & Kaxing Tianxia & ANE \\
\hline Platform foundation & Road-port & Provincial hub & Kahang hub centre \\
Mode of operation & Flatbed & Flatbed & Flatbed and self-support \\
Product & Road Express & Kaxing through truck & Timing reach \\
Brand belongs & Transfar Road-port & Kaxing Tianxia and league members & ANE \\
Integration mode & League & League & Self-support and league \\
\hline
\end{tabular}

provider and doesn't have much control. These league members is responsible for the transit lines by themselves and freely choose the store to make the delivery.

ANE: ANE can make their investment to built trunk, or unify the league's existing lines to manage. It also has participation on joining line and stores that are unified to manage uniformly.

\subsubsection{They Have Different Operational Thinking}

Transfar Road-port: It to get all sorts of road freight information provided to join platform customers by building some large highway port. Transfar Road-port presides over on both sides of the goods supplying. But the transport is decided by shipping companies, and Transfar Road-port is just as a supervision in this play.

Kaxing is just a integration platform, the shipping companies run to its own mode. They are just unified on the family and goods channels.

ANE operate on the mode of express network, it is relatively strict to the requirement of unity. All of the stores and lines below ANE should be carried out in accordance with ANE's mode, such as delivery, it must be in accordance with the unified price charge and resolutely put an end to the action of additional fees.

\subsection{Analysis on the Core Characteristics of the Road Freight Platform Mode}

Based on the research of the existing road freight platform, we can find that, in spite of this few platform have very big difference in integration details, but in the way of integration they all build isomorphic construction entity or information platform and gather road freight resources to achieve the goal of resource sharing and efficiency promotion. We can verify model features I mentioned earlier by concrete analysis.

\subsubsection{Coordinated Linked between Online and Offline}

Transfar Road-port have entity platform and its own information exchange platform, and it's function is very rich. ANE can also construct freight network hub based on the basis of overall information platform to form physical network offline. And ANE can through the large central platform, which is the core of the whole network, as the key to expand its operation. Kaxing does not seek to build such a offline hub like the way Transfar Road-port and ANE do, but it form it own entities network platform in the form of integrating existing lines and hubs, then connect with the network information platform to achieve the effect that coordinating linked between online and offline.

\subsubsection{Positive Cross Network Effects of Road Freight Platform Multilateral Market}

We see that whether Transfar Road-port, Kaxing or ANE whoes platform operation are all based on multilateral market network. The network effect formed by the multilateral market is exactly the positive cross-border network. The quantity increase in any side of the business will enhance the other sides. Each platform is also constantly doing all kinds of marketing to attract customers in order to realize the positive cycle.

\subsubsection{Ecosystem of Road Freight Platform}

The Transfar has been building a kind of eco-system which see "cars, people, goods, platforms" as the core elements. It is a collection of all elements within the entire network which around the road-port entity. The Transfar is also in creating such a resource elements, not only including direct integration resource elements, but also many indirect contact group, it can provide enough development potential for value-added activities and expanding the scale of the platform. On the other hand, the main points pushed by the Kaxing Tianxia is an eco- 
logical system which work around the card logistics communities, though this community is just like an information sharing center, it almost covered all the main body of resource factors which related to the Kaxing Tianxia. Certainly the entity space outside the community is complete ecosystem. And ANE ecosystem is using their own strength to build trunk sector, the branch sector is using joining forms, optimized the diversification layout and finally formed it's unique ecosystem.

\subsubsection{For the Purpose of Resources Integration}

What we called the Transfar Road-port, Kaxing Tianxia and ANE, the road freight platform which all these tried to bulid, is in order to realize the road freight transportation resources aggregation, thus attaining the goal of resource integration. Transfar Road-port is committed to "platform integration operators", implement the national road resources integration, expanding the size of the market, improve the degree of market concentration. What Kaxing doing is using highway hub for realizing road freight intensive integration, make the messy line groups be integrated tight line combination. ANE is committed to build China's largest alliance network of "Lessthan-Truck-Load Express”, realize the integration of the subjects, lines, and hub of the Scattered freight. These three platform is for the purpose of the road freight transportation resources integration, resources agglomeration and finally be efficient used.

\section{Conclusions}

The role of our country road freight platform to road freight resources integration has been showing results. It solved some problems of road freight market, improved the efficiency of the freight, and reduced the freight cost to a certain extent. They have made any progress all on the subject, demand, service and network integration, but there is also a certain gap of application in reality.

Along with the developing of the economy and further transforming of industrial structure, our country road freight operation structure may change as well. As the main way of the freight in China, the status of road freight transport of the goods will be more important. The scattered state of the road freight transportation resources now won't have too big change in a short period of time, but the road freight transportation platform in the middle of the road freight transportation resources integration will play a more and more important role. We should attach importance to the development of the platform. We should summarize the successes in resource integration and the direction of development from the perspective of the whole industry, and provide reference for the development of road freight transportation platform.

\section{References}

[1] Wei, L.R. (2000) The Consider from the WTO to the Construction of Road Freight Market Main Body. Comprehensive Transportation, 12, 18-20.

[2] The Ministry of Transport of the People’s Republic of China (2010) Report to the Development of China's Road Transport. China Communications Press, Beijing.

[3] Transport Union Media Group Co., LTD, Eastern Bell Benture Capital Co., LTD, Huitong Tianxia United Technology Co., LTD. (2013) China Freight Logistics Industry Report. Transport Union Institute, Beijing, 9-30.

[4] Xu, F.Y. and Ji, C. (2014) Management on Platform Company. Shanghai Jiao Tong University Press, Shanghai, 53-55.

[5] Wen, L. (2013) Coal Smart Logistic Park Platform Operation Model Research Taking Zhongyu Hantaichuan North Coal Smart Logistic Park as an Example. China University of Geosciences, Beijing, 38-43. 